\title{
Innovative Practical Ability Analysis and Upgrade Strategy of Advanced Academy Engineering Major
}

\author{
Zhao Yi Fei ${ }^{1, a}$, Zhu Wen $\mathrm{Bi}^{2, b^{*}}$ and Liu Hai Xue ${ }^{3, \mathrm{c}}$ \\ ${ }^{1}$ Tianjin Agricultural University, china \\ ${ }^{2}$ Tianjin Agricultural University , china \\ ${ }^{3}$ Tianjin Agricultural University, china \\ a 517710291@qq.com, b120627955@qq.com, ${ }^{\mathrm{c}} 514887257 @ q q . c o m$
}

Keywords: Innovative talents cultivation; Survey and research; Engineering major; Practical ability.

\begin{abstract}
Taking the undergraduate from the School of Engineering and Technology in Tianjin Agricultural University and School of Mechanics in Tianjin Polytechnic University as the investigated object, surveying on 267 college students with questionnaire, developing situation of cultivating situation about the innovative talent with engineering major from advanced universities and academies were analyzed to form the upgrade strategy for the innovative practical ability of the undergraduate with engineering major in advanced universities.
\end{abstract}

\section{Introduction}

Innovate in the talent cultivating mechanism of universities, promote the university to create the feature and strive for the top. That is not only the urgent demand of our national high educational business on the leaping development, but also the key priority for furthering the comprehensive reform in high educational field as well. Advanced university is the educational platform for cultivating the undergraduates. Cultivating innovative college students is the social responsibility at the age of endowing advanced universities. However in China, the undergraduates are subjected under the constraint of rules and regulations from exam-oriented education before the entrance, so some students always care about the test scores but neglect the integrative competence. They usually show the overdependence on the textbook knowledge while loss incredulous scientific attitude, forming the hidebound thought without stimulate their innovative ability in totally $[1,2]$. Therefore, further guiding undergraduates establish innovative consciousness, cultivating the entrepreneurship, improving the creative ability and training a generation that adapt to the future challenged high-quality talents in agriculture and forestry already become the requirement of the age for making the great China dream come true.

The research uses the questionnaire survey, taking random extractive 300 students from the School of Engineering and Technology in Tianjin Agricultural University and School of Mechanics in Tianjin Polytechnic University as the investigated object, handing out 300 and returning 267 valid questionnaires back with $89 \%$ feedback ratio (less than $2 / 3$ question answering amounts is invalid). Combined with the surveying results, developing situation about the cultivation of innovative talents with the major of engineering in the advanced university was analyzed, pointedly putting forward the countermeasures about strengthening the cultivation for the innovative talents with engineering majors in high-level university. 


\section{Current situation of cultivation of innovative talents with engineering major in advanced university}

Whether the university should put forward clear requirement for the cultivation of innovative talents in engineering major in advanced university. The results were discovered in the inquiry that $85 \%$ undergraduates considered the university should address explicit requirement for the cultivation of innovative talents with engineering major. But the requirement should be given priority to the promotion and guidance rather than oblige to be coincident. The result was shown that current undergraduates own stronger independent consciousness and diversification notion that should be fully attentive by the advanced university driving the educational job of innovative talents cultivation with engineering major. Thus, combed with the actual requirement of undergraduates, selecting the innovative talents cultivation modes with scientific, rational and strong pertinence and effectiveness in tertiary institutions is apparently crucial.

Which qualities should innovative talents own? Surveying results were displayed that $20 \%$ college students deemed that creative talents should own unique way of thinking. $25 \%$ undergraduates considered innovative talents should own the probing spirit. $28 \%$ thought creative talents should have diligence, exchanging ability, team spirit and benign morality, culture and responsibility. $21 \%$ felt innovative talents should possess high-tech attainment. From the results it can be seen that current college students had a relevantly overall and independent notion towards the basic quality the creative talents should own. But they lacked of a focused, full and precise and cognition system which is in combination with actual situation. It took negative impact on the innovative talents cultivation and personal creative ability training in the university. Reach the generalization and master everything is far away from the innovative objective. So it would be urgent for each university putting forward the understanding and focal developing direction which is adaptive towards basic quality of innovative talents meanwhile carrying out correct and accurate idea for the college students.

What was the greatest factor that impact on the undergraduates' innovative consciousness and ability? Investigated results were shown that $42 \%$ undergraduates thought the innovative notion and ability was influenced by college activities. And then personal factor is occupied in $24 \%$. Home education and class teaching is $15 \%$ respectively. But congenital factor only took $4 \%$ towards the undergraduates' innovative notion and ability. In terms of the results, it can be seen that current students addressed the greatest hope for the cultivation of innovative consciousness and creative ability. It was proved that university undertook great obligation without evasiveness. So it was more urgent and required to reinforce relevant research on the innovative talents cultivation.

What was the scarcest on the undergraduates' creation? Statistics were shown that $45 \%$ undergraduates consider the innovation was in need but the scarcest factor was atmosphere. Next one was the information and knowledge. And then it was the skill guidance and fund that occupied $18 \%$ and $12 \%$ in respectively. Positively promote the construction of innovative atmosphere. Once strong innovative atmosphere formed, innovative talents were naturally emerged like bamboo shoots after the spring rain. Otherwise, it would be hard to be innovative if the environment in the college was conservative and exclusive.

What was the biggest problem for enhancing the educational quality of innovative talents? It can be known in the investigation that what could be done to improve the quality of innovative talents' education. $40 \%$ undergraduates considered that to reform the teaching idea altering mechanical inculcation to the enlightening induce education. $20 \%$ deemed that to alter current length of schooling and establish scientific and available cultivation scheme. $15 \%$ college students thought that to construct educational innovative engineering and enhance undergraduates' innovative ability. But only $10 \%$ thought that to stop increasing the enrollment, taking the innovative ability as the referred accordance for varieties of colleges and selecting high quality source of students. Only $9 \%$ felt to better improve the evaluation system, boosting the elimination and severely mastering the cultivation object. 
Additionally, $6 \%$ held the opinion of strengthening the tutor team construction. Reform the educational theory will be gradually becoming common view. Meanwhile, changing the length of schooling, constructing the innovative engineering, stopping enlarge the enrollment, improving the evaluation system and so forth that mentioned during the survey could be seen to put forward the scientific countermeasure towards reforming the educational theory from an angel of view.

What the university should do most in teaching for the innovative talents cultivation as undergraduates thought? Surveying results were shown that what should be done for cultivating the innovative talents was that the link of practical teaching should be reformed in the teaching for the university and the laboratory should be gradually opened, 35\% undergraduates considered. Second, $25 \%$ thought that the method of examination should be reformed to encourage the students standing out who owned innovative consciousness. $25 \%$ regarded practical teaching and engineering training should be highlighted while $10 \%$ deemed participatory teaching ways in the teaching should be used. It can be seen from the results that advanced university should be approaching to increase the practical opportunity in the teaching. Opening the lab, reforming the examination ways of mechanical memorization and emphasizing the practical teach were the good measures of which the students hope and colleges could do.

What was the first step to establish the cultivating system for the innovative talents with engineering major in advanced universities that was good for the undergraduates growing and educational quality improving? Statistical results were shown that the first step was to further increase the students' practical opportunity for establishing the system of innovative talents training in the engineering major in the universities which is good for the undergraduates growing and enhancement of teaching quality, $33 \%$ college students considered. $23 \%$ chose the major setting and optional flexibility. $18 \%$ thought that independence of learning was important. $14 \%$ stressed the practical teaching while $12 \%$ were prone to the contents richness in the curriculum system. According to the results analysis, students looked forward to increasing the practical chance. The setting and answer of the question was also proved to the conclusion of former issue that higher learning institutions should be closer to the practice during the course of teaching contents setting.

What was the best way of teaching as undergraduates thought regarding to cultivate innovative talents with engineering major in advanced universities? It was developed in the survey that 55\% undergraduates considered the cultivating effect towards the innovative talents with engineering majors in the university in the ways that teachers narrated the main topic, organized and enlightened the discussion in combination with the case study was the best. And then, $32 \%$ thought the best would be the focus on the cases teaching with the organization and enlightenment. $10 \%$ regarded the teacher presented the main idea letting the students search for the data and write the paper. Only $3 \%$ deemed teacher gave a lecture in line with the textbook step by step in the finally. At this point, it can be seen that half of students put forward a method of teaching that was different from the ways most teachers never used, namely the case study with enlightenment. In fact, this method was already put into effect in the western occident countries. But our country still lagged behind. For cultivating the innovative person, reform the teaching methods are urgently necessary.

To sum up, for putting the up-to-date indication from the Communist Party into practice, meanwhile for conforming to the times requirement, reform was imperative. But with respect to the educational reform innovative talents cultivation should be one step ahead more. As the higher university, putting forward relevant talents cultivation countermeasures in combination with actual situation was in need.

\section{Countermeasures of strengthening the cultivation of innovative people with engineering major in higher university}

Undergraduates should enhance self learning and overcome the psychological disorder towards innovation. It can be seen from the situation of basic quality the innovative people owning that 
cultivating the innovative talents in agriculture and forestry should be training and intensifying the individual mind of undergraduates starting from themselves. Generally, who own strong creation with outstanding contribution in scientific technology have good individuality. If undergraduates want to promote the innovative ability, they need to establish high ideal. First is to remove the self inferiority feeling, to believe they have great potential in the innovation. Second, students should fall into the habit of certain learning and thinking, daring to break through pre-existing thinking set, playing self creativity. When Qing-shi Zhu academician summarize his improving skill of innovative ability, he said that the key point for the excellent scientists continually creating fresh achievements is that they have unexhausted interests with constantly cultivating self consciousness and concentrate on researching the issue in the finally[3].

Set up the educational concept with innovation. Cultivating the innovative talents, modern undergraduates need to be liberated from inherent conventional educational mode and theory. Precondition of cultivating the creativity of undergraduates is that teachers should recreate innovative educational theory. University only reform the education, altering the traditional teaching modes of injection and spoon feeding to the constructor of knowledge and ability, letting the students develop from simply receiving the knowledge to the active learning, strengthening the cultivation of undergraduates' innovative thinking ability.

Opening the innovative curriculum, improving the educational system. In order to fully improve the innovative ability of undergraduates, it is particularly necessary to set innovative curriculum regarding to the situation of the innovative talents cultivation in our university. The ability of letting out the thought, flexibility and reversing the thought for the undergraduates could be fully trained via opening the creative curriculum to make the students potential innovative ability step by step activate so that further the improvement for the innovative ability of our college students. For instance, students may preliminary understand the creative steps and methods towards the scientific research via the basic training on relevant innovative ability under the appropriate guidance of teachers $[4,5]$.

Teach the students in accordance of their aptitude. Carry forward students' personality characteristics. Conventional teacher as subject makes teachers and students lacking of mutual exchange and communication. Students learning initiative and creation are in limitation. For changing the teaching situation, it is necessary for the teachers to fully esteem the differentiation in the aspects of interests, ability, personality, building the rational teaching mode including taking the students as the subject, guiding by teachers and in combination with teaching and learning.

Changing the way of knowledge-transference. From the questionnaire, conventional educational approach of injection should be abandoned in the university, regarding to the problem of educational quality of innovative talents. Bringing in the modern teaching methods in the current society which is urgent of innovative ability is much more important. Teachers may import the educational methods of enlightenment, discussion, question and research, leaving the students sufficient time to think and ask. In the ways of guidance, enlightenment, showing direction and interaction between the teacher and students and also among the students, undergraduates' ability of cognition, analyzing and resolving the problem should be improved to promote the development of innovative ability [6].

Strengthen relevant research on the cultivating modes for the innovative talents. Education is an art and also a science. For complete the science, scientific approach and methods should be used on the research. As the educational administration in the university, we should endeavor to advocate the teachers participate into the research on the modes of innovative talents cultivation. Regarding to issue the journal article, for example, it should be carrying out the academic exchange between the internal and external universities, seeking for the dissemination after the experiment of the practical available cultivation modes applying on individual departments or major[7,8].

Reform the teaching theory, actively driving for the educational reform. The key for the educational reform is the teacher. Above all the innovative teachers are the first for cultivating the 
innovative students. Conclusions could be apparently shown via the survey that teaching theory reform is already gradually becoming to the consensus of teachers and students towards the implementation of educational reform. To reform the educational theory, forming the new theory of innovative talents cultivation, the author considered that the following measures could be adopted. First, check on the teachers importing, actively recruit a batch of teachers with active idea and innovative spirit who can motivate students' creative consciousness and innovative spirit. Second, send out the teachers going outside to national excellent academies or overseas to learn some innovative theory in order to open their horizon, free their mind and cultivate a group of innovative teachers indeed. Third, reform teaching evaluated system, give play to the good and innovative teachers and encourage them. Fourth, reform curriculum contents setting with increasing the chance on practice, for example, visiting the factory or farm, going to the lab to operate the experiments. Fifth, alter the teaching form. Change from the inculcation to enlightenment on education, for instance, cases teaching, let the students on the research. Sixth, reform the ways of examination and awarding. Each student is different. Everyone has his or her own advantage, but the way that determines whether he or she is good or bad in terms of the test score and giving award is not fit to the demand of the cultivation for the innovative talents[9].

Develop distinctive educational mode in combination with territory and school advantage. The university should actively establish the cooperation with relevant enterprises in Tianjin area, giving good practical opportunity to the students, sharing the resource with other universities, developing innovative activities in inter colleges. Each university has its own regional characteristics, history, unique talents group, some shortage of resource inferior position, economic burden without doubt. So, know self and others, give play to good while avert the shortage, carry out distinctive talents mode even implement some cultivating ways other universities or academies cannot do, all of which could promote the university and college to Create the Feature and Strive for the Top[10].

\section{Summary}

Cultivate the talents who own the innovative ability is the compelling obligation and irreplaceable advantage of advanced universities and academies. According to the analysis of cultivating situation about the innovative talents with engineering major from advanced universities and academies, our university should centre on the objective of innovative ability cultivation in combination with the demand and actual situation of national economic development, selecting appropriate approach, insisting on the people oriented, deepening the educational teaching reform, integrating and optimizing course system and educational teaching link, strengthening the cultivation of humanistic quality and basic skill, overall promoting students' self innovative potential via continually creating cultivation mode.

\section{References}

[1] W. Zhang, J. Zhong, N.W. Chou, W.N. He: Experiment Science and Technology, Vol. 9 (2011) No.4, p. 65-68. (In Chinese)

[2] Information on http://www.mycos.com.cn/Services/CollegeService

[3] H.X. Zhao, J.L. Bao, Z.Q. Ding: Experiment Science and Technology, Vol. 7 (2009) No.1, p. 91-92. (In Chinese)

[4] J. Zhang, J. Zhao, L. L. Zhang, W. J. Wang: Laboratory Science, Vol. 17 (2014) No.1, p. 92-94. (In Chinese)

[5] X.P. Yan, J.L Xie, Z.F. Li: Journal of Higher Education in Science \& Technology, Vol. 28 (2009) No.1, p. 74-77. (In Chinese) 
[6] S.G. Wang, R.P. Liu, X.S. Feng: Research and Exploration in Laboratory, Vol. 28 (2009) No.9, p. 117-120. (In Chinese)

[7] X.M. Chen, D.C. Sheng, D. Pu, W. Xiao, J. Zou: Laboratory Science, Vol. 15 (2012) No.6, p. 143-145. (In Chinese)

[8] Information on http://www.moe.gov.cn.

[9] J.L. Tang, F. Cheng, C.H. Huang, X.Y. Qu, X.B. Xu: Research and Exploration in Laboratory, Vol. 32 (2013) No.1, p. 88-89. (In Chinese)

[10] Q.M. Liao,G.N. Qin: Research and Exploration in Laboratory, Vol. 29 (2010) No.1, p. 162-165. (In Chinese) 